\title{
Assessment of Maternal and Fetal Outcome by Comparing Teenage Pregnancies and Primigravidae Aged 20-29 Years.
}

\author{
Dr.C.Vijayalakshmi \\ (Department of Obstetrics \& Gynecology, Government Medical College \& Hospital, Ananthapuramu, \\ Andhra Pradesh, India)
}

\begin{abstract}
Introduction: Pregnancy attained by human females younger than 20 years of age group comes under teenage pregnancies. The aim of the present study is to assess the maternal and fetal outcome and their comparison among teenage pregnancies and primigravidas of age group of 20-29 years. Materials and Methods: A prospective study was done for one year at Government Medical College, Ananthapuramu. A total of 140 Studied population were divided into two groups for ease of study. 40 patients of teenage primigravida were considered under Group I and 100 patients of primigravida with in the age group of 20-29 years. Data regarding patients details including age, socioeconomic status, antenatal visits, complications, mode of delivery, maternal and fetal outcome were observed. Results: Maternal complications like PIH, Anemia, Abruptio placenta, PROM, Oligohydramnios and Fetal Complications like Low birth, Preterm labor, IUGR, $C P D$, congenital anomalies were observed in higher percentage among teenage pregnancies when compared to primigravida within the age group of 20-29 years. 54\% of primigravida in the age group of 20-29 years and $20 \%$ of teenage pregnancies underwent normal delivery. Maternal and Neonatal Mortality rate was predominantly observed in teenage pregnancies when compared to primigravida with in the age group of 20-29 years. Conclusion: Health education regarding early sex, multiple partners, early marriage, literacy needed among teenage girls and impulse towards good antenatal care, proper treatment, contraceptive use are in need among teenage pregnancies.
\end{abstract}

Keywords: Fetal Outcome, Maternal Outcome, Teenage pregnancies, Primigravida.

\section{Introduction}

Pregnancy attained by human females younger than 20 years of age group comes under teenage pregnancies. Females of 15 years age group are less likely to have enough physically developed body to attain pregnancy [1]. Adolescent child bearing cause major adverse effects in mother and fetus. Younger age group pregnancies are more in developing countries, about 20000 girls under 18 years of age give birth every day [2]. Jacqueline E Darroch et al [3] reported various incidences of adolescent child bearing ( $<20$ years of age $)$, as in US 22\%, Great Britain 15\%, Canada 11\%, France 6\% and Sweden 4\%. Pregnancies in younger age group girls presents many problems and needs to be understood those. Many problems are being faced by teenage pregnancies, especially socioeconomic related including low socioeconomic status, family related problems, illiteracy, influence of liberal views on sex. Teenage pregnancies poses various risk factors such as anemia, pregnancy induced hypertension, preterm labor, contracted pelvis, cephalopelvic disproportion, low birth weight. Even after controlling uncontrolled antenatal care, these risk factors was observing still in teens $[4,5]$. Socioeconomic, medical and psychological impact of pregnancy and parenthood in teens were observed in many studies [6]. Children of teen mothers faces many developmental disabilities [7,8].

The aim of the present study is to assess the maternal and fetal outcome, mode of delivery and their comparison among teenage pregnancies and primigravidas of age group of 20-29 years.

\section{Materials And Methods}

A prospective study was done for one year at Government Medical College, Ananthapuramu. In this study maternal and fetal outcome was evaluated among teenage pregnancies and primigravida of age group 2029 years. Informed consent was taken from all the studied population.

All pregnant women with primigravida, who has taken regular antenatal visits were included in this study. Primigravida with induced and spontaneous abortions, molar pregnancy, didn't come for follow up were excluded from the study.

A total of 140 Studied population were divided into two groups for ease of study. 40 patients of teenage primigravida were considered under Group I and 100 patients of primigravida with in the age group of 20-29 years.

Data of studied population regarding antenatal history, obstetric history, significant past and family history was noted. A complete systemic examination was done. Obstetric and Gynecological examination was done. Patients were advised for routine \& relevant investigations and ultrasonography. Patients were advised to 
come for routine antenatal visits and to take regular medications. Pregnancy outcome was recorded in terms of type of delivery, complications, durations of labor, fetal outcome.

Data regarding patients details including age, socioeconomic status, antenatal visits, complications, mode of delivery, maternal and fetal outcome were noted and entered into excel sheet. Statistical analysis was done in the form of percentages.

\section{Results}

Teenage pregnancies of 40 patients and 100 patients of primigravida within the age group of 20-24 years age group were selected in this study. The mean age of teenage pregnancies group was $16.2 \pm 3.5$ and primigravida within the reproductive age group were $24.8 \pm 2.6$. The mean BMI of Group I and Group II were $23.6 \pm 4.6$ and $32.5 \pm 4.8$ respectively.

Antenatal complications was observed and compared between teenage pregnancies and primigravida in the age group of 20-29 years. PIH, Anemia, Abruptio placenta, PROM, Oligohydramnios were observed in higher percentage among teenage pregnancies when compared to primigravida within the age group of 20-29 years (Table No.1). Anemia (67.8\%) was the most commonly observed complication in both groups followed by PIH which was $29.2 \%$.

Table No.1 Percentage of various maternal complications among both groups

\begin{tabular}{|c|c|c|c|c|c|c|}
\hline \multirow{2}{*}{$\begin{array}{c}\text { Maternal } \\
\text { Complications }\end{array}$} & \multicolumn{2}{|c|}{ Group I (n=40) } & \multicolumn{2}{c|}{ Group II (n=100) } & \multirow{2}{*}{ Total } & \multirow{2}{*}{ Percentage (\%) } \\
\cline { 2 - 5 } & No. of patients & Percentage & No. of patients & Percentage & & \\
\hline PIH & 17 & $42.5 \%$ & 24 & $24 \%$ & 41 & 29.2 \\
\hline Eclampsia & 6 & $15 \%$ & 4 & $4 \%$ & 10 & 7.1 \\
\hline Preeclampsia & 11 & $27.5 \%$ & 20 & $20 \%$ & 31 & 22.1 \\
\hline Anemia & 33 & $82.5 \%$ & 62 & $62 \%$ & 95 & 67.8 \\
\hline Abruptio placenta & 5 & $12.5 \%$ & 6 & $6 \%$ & 11 & 7.8 \\
\hline Placenta previa & 2 & $5 \%$ & 8 & $8 \%$ & 10 & 7.1 \\
\hline Oligohydramnios & 3 & $7.5 \%$ & 6 & $6 \%$ & 9 & 6.4 \\
\hline PROM & 8 & $20 \%$ & 14 & $14 \%$ & 22 & 15.7 \\
\hline
\end{tabular}

Outcome of New born were observed in both groups. Low birth weight neonates was observed predominantly in teenage pregnancies when compared to primigravida within the age group of 20-29 years. Preterm labor, IUGR and CPD was also reported most commonly in Group I (Table No.2).

Table No.2 Fetal outcome assessment in both groups

\begin{tabular}{|c|c|c|c|c|c|c|}
\hline \multirow{2}{*}{ Fetal Outcome } & \multicolumn{2}{|c|}{ Group I } & \multicolumn{2}{|c|}{ Group II } & \multirow{2}{*}{ Total } & \multirow{2}{*}{ Percentage $(\%)$} \\
\hline & No. of patients & Percentage & No. of patients & Percentage & & \\
\hline \multicolumn{7}{|l|}{ Birth weight } \\
\hline$\geq 2500$ & 15 & 37.5 & 68 & 68 & 83 & 59.2 \\
\hline $2499-2000$ & 11 & 27.5 & 25 & 25 & 36 & 25.7 \\
\hline $1999-1500$ & 11 & 27.5 & 4 & 4 & 15 & 10.7 \\
\hline$\leq 1500$ & 3 & 7.5 & 3 & 3 & 6 & 4.2 \\
\hline Pre term labor & 12 & 30 & 22 & 22 & 34 & 24.2 \\
\hline IUGR & 28 & 70 & 17 & 17 & 45 & 32.1 \\
\hline CPD & 16 & 40 & 20 & 20 & 36 & 25.7 \\
\hline Breech presentation & 7 & 17.5 & 16 & 16 & 23 & 16.4 \\
\hline Fetal distress & 4 & 10 & 24 & 24 & 28 & 20 \\
\hline Brow presentation & 4 & 10 & 2 & 2 & 6 & 4.2 \\
\hline $\begin{array}{c}\text { Congenital } \\
\text { anomalies }\end{array}$ & 2 & 5 & 3 & 3 & 5 & 3.5 \\
\hline
\end{tabular}

$54 \%$ of primigravida in the age group of 20-29 years and $20 \%$ of teenage pregnancies underwent normal delivery. Higher percentage of operative interference and cesarean sections for delivery of baby were observed in teenage pregnancies, on comparison with primigravida in the age group of 20-29 years (Table No.1)

Table No.3 Showing different types of delivery in both the groups

\begin{tabular}{|c|c|c|c|c|}
\hline \multirow{2}{*}{ Type of Delivery } & \multicolumn{2}{|c|}{ Group I } & \multicolumn{2}{c|}{ Group II } \\
\cline { 2 - 5 } & No. of patients & Percentage (\%) & No. of patients & Percentage (\%) \\
\hline Normal delivery & 8 & 20 & 54 & 54 \\
\hline Operative interference & 18 & 45 & 28 & 28 \\
\hline Cesarean section & 24 & 60 & 18 & 18 \\
\hline
\end{tabular}


Maternal and Neonatal Mortality rate was predominantly observed in teenage pregnancies when compared to primigravida with in the age group of 20-29 years. No maternal death reported in Group II patients (Table No.4).

Table No.4 Number of Maternal and Neonatal deaths among both groups

\begin{tabular}{|c|c|c|c|c|}
\hline \multirow{2}{*}{ Mortality } & Group I & & Group II & \\
\cline { 2 - 5 } & No. of patients & Percentage (\%) & No. of patients & Percentage (\%) \\
\hline Neonatal deaths & 4 & 10 & 8 & 8 \\
\hline Maternal death & 1 & 2.5 & 0 & 0 \\
\hline
\end{tabular}

\section{Discussion}

Teenage pregnancies causes many problems related to financial, social, educational and also can lead to infant and mother death [1,2]. Globally, among adolescent mothers the incidence of premature birth and low birth weight is higher $[9,10]$.

Teenage pregnancies is becoming a major problem especially in developing countries. Many reasons are responsible for bad outcome of mother and fetus with teenage pregnancies, among which antenatal care is the one can be controlled by health education. Antenatal care is the most important which can help to reduce incidence of complications in teenage pregnancies. Nelson in 1978 [11] stated that antenatal care plays an important role in maternal and fetal outcome. When compared to booked cases those who have taken regular antenatal visits, unbooked cases faces more complications during pregnancy. More number of unbooked cases usually due to low socioeconomic status and illiteracy of patients

PIH, Anemia, Abruptio placenta, PROM, Oligohydramnios were observed in higher percentage among teenage pregnancies when compared to primigravida within the age group of 20-29 years. Bhattacharya A et al [12], Bhalerao AR et al [13], Miller HS et al [14], Jacono JJ et al [15] observed that more antenatal complications among teenage pregnancies when compared to primigravida with in the age group of 20-29 years. Anemia (67.8\%) was the most commonly observed complication in both groups followed by PIH which was $29.2 \%$. Anemia is causing major impact on maternal and fetal health especially in developing countries, contributes to $10-15 \%$ of maternal deaths [16]. Anemia is curable disease and treatment depends on severity and cause.

In the present study Low birth weight, Preterm labor, IUGR and CPD were reported most commonly in teenage pregnancies when compared to primigravida with in the age group of 20-29 years. 10\% fetal distress was observed in teenage pregnancies and $24 \%$ of fetal distress was reported in 20-29 years. In similar with this study Shravage JC [17] also reported that higher percentage of IUGR in teenage pregnancies than primigravida within the age group of 20-29 years.

$54 \%$ of primigravida in the age group of 20-29 years and $20 \%$ of teenage pregnancies underwent normal delivery. Higher percentage of operative interference and cesarean sections for delivery of baby were observed in teenage pregnancies was $45 \%$ and $60 \%$ respectively, on comparison with primigravida in the age group of 20-29 years was $28 \%$ and $18 \%$ respectively as per this study.

Shravage JC [17] observed that $21.4 \%$ normal deliveries, $51.4 \%$ patients delivered by operative interference and $27.1 \%$ by cesarean section among teenage pregnancies and in primigravida within the reproductive age group women delivered normally in $51.9 \%$ patients, $29.3 \%$ cesarean section and $25.7 \%$ delivered by forceps. Kurup AO et al [18], Lubarsky SL et al [19] also found the similar results as our study. In adolescent child bearing may have various causes and also girls physiologically not enough to become pregnant. In developing countries various reasons like socioeconomic status, illiteracy plays a major role, whereas developed countries altered sexual behavior, multiple sexual partnership, failure of contraceptive use are various causes for teenage pregnancies. Teenage pregnancies ruin the education of women, economically patient will come down and faces many problems in society.

\section{Conclusion}

Teenage pregnancies are more prone towards maternal and fetal complications such as PIH, anemia, IUGR, Preterm labor, CPD etc., when compared to pregnancy in the reproductive age group. Maternal and Fetal mortality also increases in adolescent child bearing women.

Teenage pregnancies can be preventable by comprehensive sex education to younger age group girls and access birth control. Health education regarding early sex, multiple partners, early marriage, literacy needed among teenage girls and impulse towards good antenatal care, proper treatment, contraceptive use are in need among teenage pregnancies.

\section{Acknowledgements}

We are thankful to staff of Department of Obstetrics and Gynecology for helping us while doing this study. 


\section{References}

[1]. Mayor, S. Pregnancy and childbirth are leading causes of death in teenage girls in developing countries, BMJ, 328 (7449), 2004, 1152 .

[2]. "Adolescent pregnancy" - UNFPA - United Nations Population Fund

[3]. Jacqueline, E Darroch. Susheela, Singh. Jennifer, J Frost. Differences in Teenage Pregnancy Rates Among Five Developed Countries: The Roles of Sexual Activity and Contraceptive Use, Perspectives on sexual and reproductive health, 33(6), 2001, 244281 .

[4]. Loto, OM. Ezechi, OC. Kalu, BK. Loto, A. Ezechi, L. Ogunniyi, SO. "Poor obstetric performance of teenagers: Is it age- or quality of care-related?". Journal of Obstetrics \& Gynaecology, 24 (4), 2004, 395-398.

[5]. Abalkhail, BA. Adolescent pregnancy: Are there biological barriers for pregnancy outcomes?, The Journal of the Egyptian Public Health Association, 70 (5-6), 1995, 609-625.

[6]. Stepp, G. Teen Pregnancy: The Tangled Web. vision.org, 2009.

[7]. American Academy of Pediatrics. Care of adolescent parents and their children, Pediatrics, 107 (2), $2001,429-34$. 2001. doi:10.1542/peds.107.2.429.

[8]. Hofferth, SL. Reid, L. Early Childbearing and Children's Achievement And Behavior over Time". Perspectives on Sexual and Reproductive Health, 34 (1), 2002, 41-49.

[9]. Makinson, C. The health consequences of teenage fertility. Family Planning Perspectives, 17 (3), 1985, 132-139.

[10]. The National Campaign to Prevent Teen Pregnancy 2002. Not Just Another Single Issue: Teen Pregnancy Prevention's Link to Other Critical Social Issues Retrieved May 27, 2006.

[11]. Ronald M Nelson. Physiologic correlates of puberty. Clin Obstet Gynaecol, 21, 1978, 1137-47.

[12]. Bhattachrya, A. Chowdhury, N. Teenage pimigravidas, J Obstet Gynaecol India, 36, 1986, 660.

[13]. Bhalerao, AR. Desai, SV. Dastur, NA. Outcome of teenage pregnancy, J Postgrad Med, 36(3), 1990, 136-9.

[14]. Miller, HS. Lesser, KB. Reed, KL. Adolescence and very low birth weight infants: A disproportionate association. Obstet Gynecol, $87,1996,83$

[15]. Jacono, JJ. Jacono, BJ et al. Teenage pregnancy: a consideration. Canadian Journal of Public Health, 83(3), 1992, 196-9.

[16]. S. Gopalan, V. Jain. Anemia in Pregnancy. Mudaliar and Menon's Clinical Obstetrics (10 ${ }^{\text {th }}$ ed.), Orient Longman. (Chennai, 2005) 147-50.

[17]. Shravage, JC. Maternal and Perinatal Outcome in Teenage Pregnancies as compared to Primigravidae aged 20-29 years: A Cross Sectional study, Obs \& Gynae, 5(7), 2000 July, 420-422.

[18]. Kurup, AO. Singh, VK. Pregnancy outcome in unmarried teenage nulligravida in Singapore, Int J Gynecol obstet, 30(4), 1989, 30511.

[19]. Lubarsky, SL. Schif, E et al. Obstetrics characteristics among nulliparas under age 15, Obstet Gynecol, 84, $1994,365$. 